\title{
Antenatal care utilization and associated factors from rural health extension workers in Abuna Gindeberet district, West Shewa, Oromiya region, Ethiopia
}

\author{
Birhanu Darega Gela ${ }^{1,}$, Nagasa Dida Bedada ${ }^{2}$, Fikru Tafese Jaleta ${ }^{3}$, Shimeles Ololo Sinkie ${ }^{3}$ \\ ${ }^{1}$ Department of Nursing, College of Medicine and Health Sciences, Madawalabu University, Bale-Robe, Ethiopia \\ ${ }^{2}$ Department of Public Health, College of Medicine and Health Sciences, Madawalabu University, Bale-Robe, Ethiopia \\ ${ }^{3}$ Department of Health Services Management, College of Public Health and Medical Sciences, Jimma University, Jimma, Ethiopia
}

\section{Email address:}

birhanudarega@yahoo.com (B. D. Gela), nadibefe@yahoo.com (N. D. Bedada), fikretafese@gmail.com (F. T. Jaleta), shimelessos@yahoo.com (S. O. Sinkie)

\section{To cite this article:}

Birhanu Darega Gela, Nagasa Dida Bedada, Fikru Tafese Jaleta, Shimeles Ololo Sinkie. Antenatal Care Utilization and Associated Factors from Rural Health Extension Workers in Abuna Gindeberet District, West Shewa, Oromiya Region, Ethiopia. American Journal of Health Research. Vol. 2, No. 4, 2014, pp. 113-117. doi: 10.11648/j.ajhr.20140204.12

\begin{abstract}
Developing countries has low antenatal care coverage. A new cadre of community levels health workers in Ethiopia hoped to improve maternal health problem by providing antenatal care services. However, level of antenatal care services utilization from rural health extension workers is not well known. Thus, this study aimed to assess antenatal cares utilizations and associated factors from rural health extension workers in Abuna Gindeberet district of West Shewa, Oromiya regional state, Central Ethiopia. A community-based cross-sectional study design was employed among 703 randomly identified mothers of Abuna Gindeberet district in March 2013. Data were collected through intervieweradministered questionnaire and analyzed using SPSS version 16.0 software. Descriptive, bivariate and multivariate analyses were used to determine prevalence and in identifying, associated factors of antenatal care considering p-value of 0.05 . Five hundred seventy nine $(82.4 \%)$ of the mothers had received antenatal care services during their recent pregnancy. From total mothers used antenatal care services, four hundred twenty three of them (73.1\%) received the service from health extension workers. Age, educational level of respondent, distance from health post, decision makers in household and being model family were found to be statistically significant with antenatal care services utilization from health extension workers. Antenatal care service utilization from rural health extension workers was high. Age, educational level of the respondent, distance from health post, parity, decision making way and being a model family were among the predictors of antenatal care utilization from health extension workers. Thus, focusing the identified factors could improve and sustain antenatal care services from rural health extension workers.
\end{abstract}

Keywords: Health Extension Worker, Antenatal Care

\section{Introduction}

Antenatal care (ANC) is one of the most effective health interventions for preventing maternal morbidity and mortality particularly in places where the general health status of the women is poor through counseling on nutrition, birth preparedness, delivery care and family planning options after birth. It is a good opportunity for identifying threats to mother and unborn baby's health (1). But, developing countries have low antenatal care coverage and there is wide gap of ANC between developed and developing countries mothers. In developed countries, $97 \%$ of women make at least one ANC visit. In developing countries coverage of at least one ANC visit is low; that $69 \%$ in Sub-Saharan Africa and $54 \%$ in Asia (2).

Complications of pregnancy and childbirth are the leading causes of disability and death among women in the reproductive age (15-49) groups in developing countries (3). Every year some 536,000 women die of complications during pregnancy or childbirth of which $99 \%$ of them are in developing countries (4).

A woman who gives birth in Sub- Saharan Africa is 300 times more likely to die from complications related to pregnancy or childbirth compared to her counter-part living 
in a developed country (5). Ethiopia is also one of the countries with highest maternal mortality ratios in the world (6).

The Health Extension Program (HEP) was introduced during the second phase of Ethiopia's Health Sector Development Program (HSDP), since 2002/3. It is a new initiative community - based health care delivery system aimed at provision of essential services to reach the people at the grassroots level (7). It is the main vehicle for bringing key maternal, neonatal and child health interventions to the community through a new cadre of health extension workers in Ethiopia. However, only 9\% of women received ANC from these health extension workers (HEW) $(6,8)$. There are few studies on ANC services utilizations from health extension workers. Thus, this study aimed to determine prevalence of ANC utilizations and associated factors from health extension workers of Abuna Gindeberet district of West Shewa, Oromiya Regional State, Central Ethiopia.

\section{Methodology}

\subsection{Study Setting and Participation}

Community based cross sectional study conducted among seven hundred three women who gave birth in the last twelve months in Abuna Gindeberet district, West Shewa Zone, Oromiya Regional State in March 2013. The district has forty-two rural kebeles from which fourteen of them were randomly selected. Households with under oneyear child were identified through census and sampling frame was developed. Finally, study subjects were addressed through systematic random sampling (9).

The sample was determined using single population proportion formula with an assumption of: level of confidence of the study $95 \%$, sampling error tolerated $5 \%$, proportion of ANC (P) $50 \%$ and $10 \%$ non-response rate. Design effects of two were also considered because of the two sampling techniques.

\subsection{Instruments and Data Collection Methods}

Structured questionnaire, which address the objectives of the study, was adapted from pertinent literatures. The questionnaires was translated into the local language - Afan Oromo and retranslated to English. Pre-test was done on 5\% of the sample size in kebeles different from those selected kebeles before actual data collection. House to house data collection was made through interviewer administered questionnaires.

\subsection{Data Processing and Analysis}

Data entered into EpiData Version 3.1 and exported to SPSS version 16.0 for an analysis. Descriptive analysis was made to determine the prevalence of ANC utilization from health extension workers. Bivariate and multivariate analyses were used to identify associated factor of antenatal care service utilization from HEWs; accordingly, a p-value of 0.05 was considered to identify significantly associated variables.

\subsection{Ethical Considerations}

Ethical clearance and approval was obtained from the Ethical review Committee of the College of Public Health and Medical Sciences, Jimma University. Permission was obtained from district Health office. Oral informed consent obtained from participants. Confidentiality and anonymity ensured. Participants were informed that their participation were voluntary.

\section{Results}

\subsection{Socio-Demographic Characteristics}

Table 1. Socio-demographic characteristics of respondents in Abuna Gindeberet district, West Shewa Zone, Central Ethiopia, March 2013

\begin{tabular}{lll}
\hline Variables & Number $(\mathbf{n}=\mathbf{7 0 3})$ & Percent (\%) \\
\hline Educational status & & \\
$\quad$ No education & 316 & 45.0 \\
$\quad$ Only read and write & 110 & 15.6 \\
$\quad$ Primary education & 233 & 33.1 \\
$\quad$ Secondary education & 44 & 6.3 \\
Religion & & \\
$\quad$ Protestant & 525 & 74.7 \\
$\quad$ Orthodox & 122 & 17.3 \\
$\quad$ Wakefata & 56 & 8.0 \\
Occupation & & \\
$\quad$ Housewife & 648 & 92.2 \\
$\quad$ Government employee & 22 & 3.1 \\
$\quad$ Private Employee & 33 & 4.7 \\
Marital Status & & \\
$\quad$ Married & 681 & 96.9 \\
$\quad$ Single & 22 & 3.1 \\
Distance of house from health post & & \\
$\quad$ <2 km & 380 & 54.1 \\
$\quad$ 2-5km & 167 & 23.8 \\
$\quad>5 \mathrm{~km}$ & 156 & 22.2 \\
Household status towards as & & \\
model family & & \\
$\quad$ Did not hear about model & 22 & 3.1 \\
family & & \\
$\quad$ Have heard but not at all & 66 & 9.4 \\
working towards graduation & & \\
$\quad$ Working towards graduation & 472 & 20.3 \\
$\quad$ Graduated as model family & 143 & \\
\hline & &
\end{tabular}

Seven hundred three mothers were participated in the study with a response rate of $98.7 \%$. The mean age of the respondents was 31.5 ( $\mathrm{SD} \pm 7.34$ ) years. Protestants account for the highest proportion in the religious distribution 525 (74.7\%) followed by Orthodox (17.4\%). Forty five percent of the respondents had not attended any form of education. Six hundred eighty one $(96.9 \%)$ of the respondents were married (Table 1).

\subsection{Antenatal Care services Utilization}

Six hundred sixty nine $(95.2 \%)$ of the respondents had heard about ANC services. Health extension workers were 
the source of information for $509(76.1 \%)$ of the respondents had ever heard the service. Five hundred seventy nine $(82.4 \%)$ of the respondents took ANC services at least once and only 177 (30.6\%) of the respondents took World Health Organization recommended number of ANC services for their recent child pregnancy. Being free from any health problem during pregnancy was the major reasons for not attending ANC service. From the total five hundred seventy nine respondents received ANC service for their recent child pregnancy, $423(73.1 \%)$ of them took the service from health extension workers (Table 2).

Table 2. Antenatal Care Services Utilizations from Rural Health Extension Workers in Abuna Gindeberet Woreda, West Shewa Zone, Central Ethiopia in March 2013

\begin{tabular}{|c|c|c|}
\hline Variables & $\begin{array}{l}\text { Number } \\
(n=703)\end{array}$ & $\begin{array}{l}\text { Percent } \\
(\%)\end{array}$ \\
\hline \multicolumn{3}{|l|}{ Having information on $\mathrm{ANC}$} \\
\hline Yes & 669 & 95.2 \\
\hline No & 34 & 4.8 \\
\hline \multicolumn{3}{|l|}{ Sources of information on ANC } \\
\hline Radio & 63 & 9.4 \\
\hline HEWs & 509 & 76.1 \\
\hline Health professional & 91 & 13.6 \\
\hline TBAs & 6 & 0.8 \\
\hline \multicolumn{3}{|c|}{ Received ANC service for their recent child pregnancy } \\
\hline Yes & 579 & 82.4 \\
\hline No & 124 & 17.6 \\
\hline \multicolumn{3}{|l|}{ Reason for not using ANC } \\
\hline No knowledge about ANC & 26 & 20.6 \\
\hline Being in a state of good health & 54 & 43.7 \\
\hline Far from my home & 21 & 17.4 \\
\hline Too busy & 8 & 6.3 \\
\hline Waiting time is too long & 15 & 12.0 \\
\hline \multicolumn{3}{|l|}{ Service Provider visited for ANC } \\
\hline Health Post /HEWs/ & 423 & 73.1 \\
\hline Other health professionals & 156 & 26.9 \\
\hline \multicolumn{3}{|c|}{ Main reason initiated for $\mathrm{ANC}$ follow up } \\
\hline Health problem & 93 & 16.1 \\
\hline To start regular check up & 486 & 83.9 \\
\hline \multicolumn{3}{|c|}{ Reasons for not using from health extension workers } \\
\hline Poor quality service & 71 & 45.5 \\
\hline Facility not open regularly & 27 & 17.3 \\
\hline Not heard as they gave & 43 & 27.6 \\
\hline \multicolumn{3}{|c|}{ Number of ANC visits during pregnancy } \\
\hline One visit & 91 & 15.6 \\
\hline Two visits & 239 & 41.3 \\
\hline Three visits & 72 & 12.5 \\
\hline Four and more visits & 177 & 30.6 \\
\hline
\end{tabular}

\subsection{Associated Factors for ANC Service Utilizations from Health Extension Workers}

Bivariate logistic regression analysis was used to identify associated factors with ANC service utilization from rural HEWs. Accordingly, age, educational status of respondents, parity, household distance from health post, decision making way and being a model family were statistically associated with ANC service utilization from rural Health Extension workers. However, Occupation of respondent, educational status of respondents' husband and occupation of respondents' husband did not show statistically significant association with antenatal care utilization of the respondents. Through multivariate logistic regression analysis the same variables were independently associated with ANC service utilization from rural health extension workers (Table-3).

Table 3. Association of factors with antenatal care services utilization from rural health extension workers in Abuna Gindeberet District, West Shewa Zone, Central Ethiopia, March 2013

\begin{tabular}{|c|c|c|c|}
\hline Variables & Number (\%) & $\begin{array}{l}\text { COR (P- } \\
\text { value) }\end{array}$ & $\operatorname{AOR}(95 \% \mathrm{CI})$ \\
\hline \multicolumn{4}{|c|}{ Age of respondent } \\
\hline $18-24$ years & 134(19.1) & $1.33(0.001)$ & $2.49(1.44-4.30)^{*}$ \\
\hline 25-34 years & $304(43.2)$ & $1.29(0.003)$ & $2.18(1.57-3.91)^{*}$ \\
\hline $35 \&$ above & $265(37.7)$ & 1.00 & 1.00 \\
\hline \multicolumn{4}{|c|}{ Educational level of respondent } \\
\hline No education & $426(60.6)$ & $0.45(0.000)$ & $0.22(0.13-0.36)^{*}$ \\
\hline $\begin{array}{r}\text { Primary } \\
\text { education }\end{array}$ & $277(39.4)$ & 1.00 & 1.00 \\
\hline \multicolumn{4}{|l|}{ Parity } \\
\hline $1-2$ & $105(14.9)$ & 1.00 & 1.00 \\
\hline $3-4$ & $291(41.4)$ & 0.99 & $0.97(0.78-0.98)^{*}$ \\
\hline $5 \&$ above & $307(43.7)$ & $0.79(0.000)$ & $0.70(0.60-0.81)^{*}$ \\
\hline \multicolumn{4}{|c|}{ Household distance from Health Post } \\
\hline$<2 \mathrm{~km}$ & $380(54.0)$ & $1.48(0.000)$ & $3.73(2.34-5.95)^{*}$ \\
\hline $2-5 \mathrm{~km}$ & $167(23.8)$ & $1.40(0.001)$ & $2.47(1.96-3.79)^{*}$ \\
\hline$>5 \mathrm{~km}$ & $156(22.2)$ & 1.00 & 1.00 \\
\hline \multicolumn{4}{|l|}{ Model family } \\
\hline Yes & $143(20.4)$ & 1.00 & 1.00 \\
\hline No & $560(79.6)$ & $0.17(0.000)$ & $0.06(0.03-0.11)^{*}$ \\
\hline \multicolumn{4}{|c|}{ Decision making way } \\
\hline Wife & $79(11.3)$ & $11.947(0.000)$ & $8.108(3.24-20.29)^{*}$ \\
\hline Husband & $61(8.7)$ & $1.491(0.308)$ & $1.162(0.53-2.56)$ \\
\hline Both together & $563(80.0)$ & 1.00 & 1.00 \\
\hline \multicolumn{4}{|c|}{ Occupation of respondent } \\
\hline Housewife & $648(92.2)$ & $0.99(0.26)$ & \\
\hline Employed & $55(7.8)$ & 1.00 & \\
\hline \multicolumn{4}{|l|}{$\begin{array}{l}\text { Occupation of } \\
\text { husband }\end{array}$} \\
\hline Farmer & $547(77.8)$ & 1.00 & \\
\hline Employed & $89(12.7)$ & $1.43(0.76)$ & \\
\hline \multicolumn{4}{|c|}{ Educational level of husband } \\
\hline No Education & $174(23.8)$ & 1.000 & \\
\hline $\begin{array}{l}\text { Primary } \\
\text { education \& } \\
\text { above }\end{array}$ & $529(76.2)$ & $0.75(0.68)$ & \\
\hline
\end{tabular}

$*$ P-value $<0.0$

Respondents whose ages were below 35 years were more likely to utilize ANC services from rural health extension worker than older respondents $(\mathrm{OR}=2.49,95 \% \mathrm{CI}=1.44$, 4.30). Lacking formal education reduces ANC service utilization from rural health extension workers $(\mathrm{OR}=0.219$, $95 \% \mathrm{CI}=0.134,0.357)$. Distance of the residence of the respondents from health post showed significant association with ANC service utilization. Respondents who dwell in a distance of less than five kilometers were more likely to utilize ANC services than mothers who were at more than five kilo meters from their kebele's health post $(\mathrm{OR}=3.727,95 \% \mathrm{CI}=2.336,5.945)$ (Table-3). 


\section{Discussion}

The study aimed at demonstrating the utilization level of antenatal care from rural health extension workers (HEWs), and examined factors that predict the maternal health services utilization from HEWs in the study area.

From the total five hundred seventy nine had utilized ANC service for their recent child pregnancy, 423 (73.1\%) of them took ANC services from rural health extension workers. But, Ethiopia Demographic and Health Survey of 2011 showed lower ANC service utilization among reproductive age women of Oromiya regional state, which was $(9.1 \%)(6)$. This difference might be due the scope of the studies which was national wide in the case of EDHS and only one district in the case of this study. There might be also inclusion of district with very low ANC service utilization in the case of EDHS. In addition, study conducted in Tigray region showed that $163(22.5 \%)$ of the mothers visited health extension workers before delivery, which is lower than ANC service utilization in this study (10). The difference is might be due to study time and study population difference, which was under five-child mother in the case of Tigray and under one year child mother in this study. Study done in Yem special woreda in 2008 revealed that ANC services utilization from health post was $54 \%$; which is different from the finding of this study (12). The difference might come from socio-demographic difference two study populations.

The explanatory variables that identified as determinant factors of ANC services utilization from HEWs were: educational status, parity, age of the respondents', distance from health post, decision making way and being a model family. Research conducted in Yem special woreda, Southwestern Ethiopia in 2008 also showed that education, distance from health facilities and husband's approval (discussion making ways in the case of this study) were among the determinant factors of ANC service utilization (12).

Also according to study on Factors affecting the utilization of antenatal care in developing countries: systematic review of the literature in 2007; maternal education, husband's education, marital status, availability, cost, household income, women's employment, media exposure and having a history of obstetric complications were determinant factors that affect ANC services utilization (13).

Among Tigray Ethiopia women also educational status and proximity to health facility showed significant association with ANC service utilization. However, occupation of husband of the respondents that was insignificant in this study was significantly associated among Tigray women. Socio-demographic factors are probably the why of the difference (14).

As the data collection method was interviewer administered, it has contribution for accuracy of the data collected by explaining unclear points for respondents. Only the quantitative method of data collection was used and it is not triangulated with qualitative methods of data collection. Therefore, the other interested researcher on this topic is better if include qualitative methods.

\section{Conclusion}

Antenatal care service utilization from rural health extension workers was high. Age, educational level of the respondent, parity, distance from health post, decision making way and being a model family were among the predictors of antenatal care utilization from health extension workers. Thus, focusing the identified factors could improve and sustain antenatal care services from rural health extension workers.

\section{Competing Interests}

None of the authors has any competing interest.

\section{Authors' Contributions}

BD, FT \& SO conceived and designed the study. BD and FT analyzed the data and interpreted the results. ND prepared the manuscript and assisted the analysis. BD \& ND critically reviewed the manuscript. All authors have read and approved this manuscript.

\section{Acknowledgements}

We would like to thank Jimma University that this research would not have been possible without the financial support of it. Our thanks also extend to all staffs of Abuna Gindeberet health office, especially Mr Warku Kenani Benti (Head of health office) who facilitated the conditions for data collection activities, data collectors and study participants.

\section{References}

[1] WHO, UNICEF, UNFPA, World Bank. Trends in maternal mortality 1990-2008, 2010.

[2] Aminah K. Factors determining utilization of postpartum care services in Uganda, 2010.

[3] WHO, Geneva. Maternal health and safe motherhood progress report update, 2009.

[4] UNFPA. In-depth Analysis of the Ethiopian Demographic and Health Survey 2005, Addis Ababa, 2008.

[5] Annan K. and Yunus M. African in progress panel, 2010.

[6] Calverton, Maryland, USA. Ethiopia Demographic and Health Survey, 2011, Addis Ababa, Ethiopia, 2012.

[7] FMOH. Health Extension Workers, Health Post Performance, Community Satisfactions and Perception Evaluation in Rural Ethiopia, Addis Ababa, Ethiopia, 2010.

[8] Regassa N. Antenatal and postnatal cares utilizations in Southern Ethiopia, 2012. 
[9] Socio-Economic Profile of Abuna Gindeberet District. Abuna Gindeberet Woreda Profile, 2011.

[10] Medhanyie A, Spigt M, et al. The role of health extension workers in improving utilization of maternal health services in rural areas in Ethiopia: a cross sectional study, 2012.

[11] Medhanyie A, Spigt M, Dinant G, Blanco R, et al. Knowledge and performance of the Ethiopian health extension workers on antenatal and delivery care : a crosssectional study, Tigray region, Ethiopia. 2012.
[12] Tewodros B., G/Mariam A. and Dibaba Y. Factors affecting antenatal care utilization in Yem Special woreda, southwestern Ethiopia, 2008.

[13] Simkhada B, et al. Factors affecting the utilization of antenatal care in developing countries: systematic review of the literature, 2007.

[14] Tsegayet al. Determinants of antenatal and delivery care utilization in Tigray region, Ethiopia: a cross-sectional study. International Journal for Equity in Health 2013,12:30 